\title{
Article
}

Doi 10.5943/sif/5/1/2

\section{Isolation and identification of microfungi from soils in Serdang, Selangor, Malaysia}

\section{Mohd Nazri NIA ${ }^{1}$, Mohd Zaini NA ${ }^{1}$, Aris $A^{1}$, Hasan ZAE ${ }^{1}$, Abd Murad NB${ }^{1}$, Yusof MT $^{2}$ and Mohd Zainudin NAI ${ }^{1}$}

\author{
${ }^{1}$ Department of Biology, Faculty of Science, Universiti Putra Malaysia, 43400 Serdang, Selangor, Malaysia \\ ${ }^{2}$ Department of Microbiology, Faculty of Biotechnology and Biomolecular Sciences, Universiti Putra Malaysia, 43400 \\ Serdang, Selangor, Malaysia
}

Mohd Nazri NIA, Mohd Zaini NA, Aris A, Hasan ZAE, Abd Murad NB, Yusof MT, Mohd Zainudin NAI 2020 - Isolation and identification of microfungi from soils in Serdang, Selangor, Malaysia. Studies in Fungi 5(1), 6-16, Doi 10.5943/sif/5/1/2

\begin{abstract}
Microfungi are commonly inhabited soil with various roles. The present study was conducted in order to isolate and identify microfungi from soil samples in Serdang, Selangor, Malaysia. In this study, the soil microfungi were isolated using serial dilution technique and spread plate method. A total of 25 isolates were identified into ten genera based on internal transcribed spacer region (ITS) sequence analysis, namely Aspergillus, Clonostachys, Colletotrichum, Curvularia, Gliocladiopsis, Metarhizium, Myrmecridium, Penicillium, Scedosporium and Trichoderma consisting 18 fungi species. Aspergillus and Penicillium species were claimed as predominant microfungi inhabiting the soil. Findings from this study can be used as a checklist for future studies related to fungi distribution in tropical lands. For improving further study, factors including the physicochemical properties of soil and anthropogenic activities in the sampling area should be included.
\end{abstract}

Key words - Aspergillus - diversity - fungi - Penicillium - Trichoderma

\section{Introduction}

The soil serves as a reservoir for many microbial communities of various plants which can be a part of $\mathrm{CO}_{2}$ and the nitrogen cycle. The microorganisms include fungi that play a significant role in the soil ecosystem. According to Zifcakova et al. (2016) and Maron et al. (2018), fungi have the ability to break down all kinds of organic matter, decomposing the components of soil and regulating the balance of carbon and nutrients. In daily human life, microfungi have been used in both industrial and commercial purposes such as food, medicine, and chemical. For instance, various cheeses in the food industry are produced from Penicillium roquefortii which can enrich the cheese with a pungent and robust flavor (Ropars et al. 2017). Aspergillus species have been utilized in making sodas and soft drinks as an alternative way of producing citric acid (Oladele et al. 2014). Microfungi are also contributing to the medicinal industry as Penicillium species naturally produce antibiotics (penicillin) that contributed to the discovery of highly effective antibiotics (Ziemons et al. 2017). Those beneficial microfungal species can be obtained by isolating them from various habitats including soil (Tedersoo et al. 2014).

However, populations of soil microfungi are being threatened and need to be conserved as part of biodiversity. According to Tedersoo et al. (2014), the richness of fungal species is declining 
as they found a huge gap between known and described species and the actual numbers of different fungi in the world of soils. Nowadays, the study on the fungi in Asian countries including Malaysia is limited (Hyde 2003, Lee et al. 2012). Based on various publication resources, about 1141 species of Ascomycota fungi have been documented for Malaysia, but still, there are numerous undiscovered species (Lee et al. 2012).

This study contributes additional information for the related organization about the source of beneficial microfungi. Hence, the objectives of this study are to examine morphological characteristics of microfungi isolated from soil samples throughout Serdang, Selangor, and to identify the isolated microfungi into species level based on internal transcribed spacer (ITS) sequence analysis.

\section{Materials \& Methods}

\section{Sampling}

Four sampling sites in Serdang, Selangor were selected as the study areas (Table 1). The temperature in this area reaches a maximum of $33^{\circ} \mathrm{C}$ and minimum $23^{\circ} \mathrm{C}$ with $27^{\circ} \mathrm{C}$ as an average temperature. Average humidity is $70 \%$ (80\%, maximum and $66 \%$, minimum), whereas the annual average rainfall is $187 \mathrm{~mm}$ (http://www.met.gov.my/). The atmosphere pressure is 1008.7 to 1011.5 mb (https://www.worldweatheronline.com/). The samples were collected in 2018 with five plots per site as replicates. Quadrat sampling was conducted in the sampling areas, where a rectangle marked out with area $20 \times 20 \mathrm{~m}$ was measured on the ground by measuring tape (Mueller et al. 2004). All plots were randomly selected for soil sampling. The soil samples were collected from each plot near roots of tree. The soil was dug for 8 to $10 \mathrm{~cm}$ deep by using a soil corer and was collected with a clean polythene bags using a clean scoop. The collected samples were brought to the Laboratory of Mycology for further analysis.

Table 1 Four sampling sites located in Serdang, Selangor

\begin{tabular}{clll}
\hline Sampling site & Name of the sampling site & \multicolumn{1}{c}{ GPS } & Type of land use \\
\hline 1. & Oil palm plantation & $2^{\circ} 59^{\prime} 18.8^{\prime \prime} \mathrm{N}, 101^{\circ} 43^{\prime} 20.7^{\prime \prime} \mathrm{E}$ & Agricultural \\
2. & Bukit Ekspo & $2^{\circ} 59^{\prime} 21.6^{\prime \prime} \mathrm{N}, 101^{\circ} 42^{\prime} 38.7^{\prime} \mathrm{E}$ & Recreational \\
3. & Lawn of Rumah Muzik & $3^{\circ} 00^{\prime} 01.7^{\prime \prime} \mathrm{N}, 101^{\circ} 42^{\prime} 10.8^{\prime \prime} \mathrm{E}$ & Residential \\
4. & Lawn of Panggung Percubaan & $3^{\circ} 00^{\prime} 01.5^{\prime} \mathrm{N}, 101^{\circ} 42^{\prime} 26.4^{\prime} \mathrm{E}$ & Residential \\
\hline
\end{tabular}

\section{Fungal isolation and purification}

Fungal isolation was performed using serial dilution method (Apinis 1963) and cultured on Potato dextrose agar (PDA) and Rose Bengal agar (RBA). The diluents from each dilution were pipetted about $1 \mathrm{ml}$ onto a different surface of PDA and were spread evenly over the surface of agar using a sterile glass rod L-shaped. The diluents from test tubes were then pipetted $1 \mathrm{ml}$ into an empty plate using a sterile pipette. The molten RBA was poured into the plates and the plates were swirled until the agar sets. Each dilution factor for PDA and RBA media were conducted in three replicates and were incubated in an incubator at $28^{\circ} \mathrm{C}$ for 48 to 72 hours. All fungal cultures were purified using streaking dilution technique. The inoculum was spread by making a wider stroke on the surface of new fresh PDA. The plate was sealed and was replaced in the incubator for $28^{\circ} \mathrm{C}$ for 24 hours to allow the growth of the colony. A pure and visible growth of fungi was obtained using hyphal tip technique on the PDA plates.

The pure isolated microfungi were preserved in the short term for working cultures, and longterm for stock cultures. Filter paper technique (Fong et al. 2000) and 25\% glycerol complete medium with xylose (CMX) conidial suspension stock solution was utilized for long-term preservation of microfungi, while half PDA media were used for working cultures. 


\section{Morphological observation}

The fungal characteristics were observed based on the macromorphological characteristics on PDA including the colony color, pigmentation of the colony and the texture of the colony. Micromorphological characteristics such as the types of conidiophores, the presence of chlamydospores, the arrangements of conidia, the shape of microconidia and the shape of macroconidia were observed by using slide cultures. The slide was observed using a compound light microscope (CX31RBSFA, Olympus Corporation). The images were captured using Dino Capture 2.0 (ANMO Electronics Corporation, Taiwan).

\section{DNA extraction}

All isolates were preceded to molecular identification using ITS sequence analysis. The isolates were cultured on PDA and incubated for 5 days. DNA of the isolates was extracted using UltraClean ${ }^{\circledR}$ Microbial DNA Isolation Kit (MO BIO, Carlsbad, CA, USA) according to manufacturer's instructions.

\section{PCR amplification}

The microfungi DNA was amplified by using $8.0 \mu$ of $5 \times$ Green GoTaq buffer, dNTP stock mixture which is $4.0 \mu \mathrm{L}(2 \mathrm{mM}), 4.0 \mu \mathrm{L}$ of $\mathrm{MgCl} 2(25 \mathrm{mM}), 0.2 \mu \mathrm{L}$ of Taq DNA polymerase, 2.0 $\mu \mathrm{L}$ of each primer $(10 \mathrm{mM}), 17.8 \mu \mathrm{L}$ of nuclease-free water, and $2.0 \mu \mathrm{L}$ of genomic DNA with an overall volume of $40 \mu \mathrm{L}$. The ITS primers used are ITS1 (5'-TCCGTAGGTGAACCTGCGG-3') and ITS4 (5'-TCCTCCGCTTATTGATATGC-3') to amplify the ITS sequences (White et al. 1990). The PCR protocol were set as follows: initial denaturation for 30 seconds at $95^{\circ} \mathrm{C}$, followed by 35 cycles of denaturation $\left(95^{\circ} \mathrm{C}\right.$ for 10 seconds), annealing $\left(59^{\circ} \mathrm{C}\right.$ for 15 seconds) and extension $\left(72^{\circ} \mathrm{C}\right.$ for 30 seconds), and was completed by a final extension step at $72^{\circ} \mathrm{C}$ for 5 minutes.

\section{Gel electrophoresis}

The PCR products were gel-electrophoresed using 1.5\% agarose gel. The mixture of $2.5 \mu \mathrm{L}$ of $6 \times$ loading dye and $2.5 \mu \mathrm{L}$ of $100 \mathrm{bp}$ DNA marker were used as a ladder. The DNA and ladder were pipetted with $5 \mu \mathrm{L}$ in volume into the holes by using a micropipette and electrophoresed. The amplicon size was visualized under a UV trans-illuminator.

\section{Sequence analysis}

The PCR products were purified using a QIAquick gel extraction kit (QIAGEN, USA), following the manufacturer's procedure. The purified PCR products were sequenced by using an Applied Biosystem 3730xl DNA Analyzer (MyTACG Bioscience Company, MY). Sequences of ITS were analysed using Molecular evolutionary genetics analysis (MEGA) 7.0 software to obtain alignment sequences (Kumar et al. 2016). The BLAST (https://blast.ncbi.nlm.nih.gov/Blast.cgi) was used to find homologous sequences from the NCBI GenBank (https://www.ncbi.nlm.nih.gov/).

\section{Phylogenetic tree}

Phylogenetic tree was constructed using Neighbor-Joining (NJ) method in MEGA 7.0. Tamura-Nei model used to as a substitution model with 1000 bootstrap replicates to test of phylogenetic tree (Tamura et al. 2013). Saccharomyces boulardii was chosen as the out-group. All new sequences were deposited at the GenBank database (https://www.ncbi.nlm.nih.gov/genbank/).

\section{Results}

Ten genera were determined in the present study including Aspergillus, Clonostachys, Colletotrichum, Curvularia, Gliocladiopsis, Metarhizium, Myrmecridium, Penicillium, Scedosporium and Trichoderma. In results, 18 species were successfully identified with percentage similarity ranged from $91 \%$ to $100 \%$, where four species from Aspergillus (A. aculeatinus, A. aculeatus, A. nomius and A. tamarii), five from Penicillium ( $P$. javanicum, $P$. oxalicum, $P$. panissanguineum, $P$. rolfsii and $P$. singorense) and 1 species belongs to Clonostachys (C. rosea $f$. 
catenulata), Colletotrichum (C. gloeosporioides), Curvularia (C. lunata), Gliocladiopsis (G. peggii), Metarhizium (M. anisopliae), Myrmecridium (M. schulzeri), Scedosporium (S. boydii) and Trichoderma (T. koningiopsis). The identified species name, size of deposited sequences and GenBank accession number for 25 selected microfungi are listed in Table 2.

Table 2 GenBank accession numbers of deposited microfungal isolates.

\begin{tabular}{|c|c|c|c|c|c|}
\hline No. & Isolates & Species & Sampling site & $\begin{array}{l}\text { Size } \\
\text { (bp) }\end{array}$ & $\begin{array}{c}\text { GenBank } \\
\text { accession } \\
\text { number }\end{array}$ \\
\hline 1. & B2819 & Aspergillus aculeatinus & Lawn of Rumah Muzik & 522 & MK204521 \\
\hline 2. & В3017 & Aspergillus aculeatus & Bukit Ekspo & 552 & MK204506 \\
\hline 3. & B3046 & Aspergillus aculeatus & Lawn of Panggung Percubaan & 522 & MK204507 \\
\hline 4. & B2786 & Aspergillus nomius & Oil palm plantation & 551 & MK204524 \\
\hline 5. & B2990 & Aspergillus tamari & Bukit Ekspo & 619 & MK204509 \\
\hline 6. & B3042 & Clonostachys rosea f. catenulata & Lawn of Rumah Muzik & 569 & MK204505 \\
\hline 7. & B2853 & Colletotrichum gloeosporioides & Bukit Ekspo & 573 & MK204517 \\
\hline 8. & B3068 & Colletotrichum gloeosporioides & Lawn of Panggung Percubaan & 577 & MK204518 \\
\hline 9. & B2836 & Curvularia lunata & Bukit Ekspo & 684 & MK204512 \\
\hline 10. & B2985 & Curvularia lunata & Bukit Ekspo & 679 & MK204511 \\
\hline 11. & B2852 & Gliocladiopsis peggii & Bukit Ekspo & 550 & MK204519 \\
\hline 12. & B2968 & Metarhizium anisopliae & Oil palm plantation & 561 & MK204515 \\
\hline 13. & B2988 & Myrmecridium schulzeri & Bukit Ekspo & 542 & MK204510 \\
\hline 14. & B2972 & Penicillium javanicum & Bukit Ekspo & 547 & MK204513 \\
\hline 15. & В3049 & Penicillium javanicum & Lawn of Panggung Percubaan & 547 & MK204514 \\
\hline 16. & B3056 & Penicillium javanicum & Lawn of Panggung Percubaan & 560 & MK226178 \\
\hline 17. & B2781 & Penicillium oxalicum & Oil palm plantation & 571 & MK204525 \\
\hline 18. & B2982 & Penicillium oxalicum & Lawn of Rumah Muzik & 571 & MK204526 \\
\hline 19. & B3030 & Penicillium oxalicum & Lawn of Rumah Muzik & 571 & MK204527 \\
\hline 20. & B3087 & Penicillium panissanguineum & Lawn of Panggung Percubaan & 587 & MK204503 \\
\hline 21. & B3014 & Penicillium rolfsii & Bukit Ekspo & 597 & MK204508 \\
\hline 22. & B2851 & Penicillium singorense & Bukit Ekspo & 560 & MK204520 \\
\hline 23. & B2773 & Scedosporium boydii & Oil palm plantation & 606 & MK204523 \\
\hline 24. & B2811 & Scedosporium boydii & Oil palm plantation & 607 & MK204522 \\
\hline 25. & B2862 & Trichoderma koningiopsis & Bukit Ekspo & 563 & MK204516 \\
\hline
\end{tabular}

Aspergillus species growth on PDA showed various color on the upper surface including black, brown, white and green (may green to earth green). The pigmentation of the colony on the reverse plate ranged from white, cream and ivory to light yellow (Fig. 1). Microscopic features are shown by Aspergillus species have swollen part known as vesicle at the end of the conidiophore. Vesicle holds phialide only on uniseriate conidiophore, while it holding metulae and phialide on biseriate conidiophore. Most of the species from genera Aspergillus produced globose to subglobose and smooth or rough wall conidia in chain arrangement.

Clonostachys species produced pale yellow with the white color of the colony on the upper surface on PDA. They produced light yellow pigmentation on the reverse plate (Fig. 1). The conidiophore bears the conidia at tips. Ellipsoidal conidia are formed and can be observed in a cluster arrangement. Colletotrichum species often produced numerous black mass conidia that slowly grow on PDA. The colony pigmentation ranged from white and cream to black, where some of the species produced the pigment in the concentric ring (Fig. 1). Most of the formation of conidia for Colletotrichum species occurred in a false head arrangement. At the tips of simple and short conidiophore, cylindrical and falcate conidia were formed. This genus can be recognized from the formation of appressoria at the end of hyphal branches. In addition, Curvularia species were 
isolated and identified in the present study.

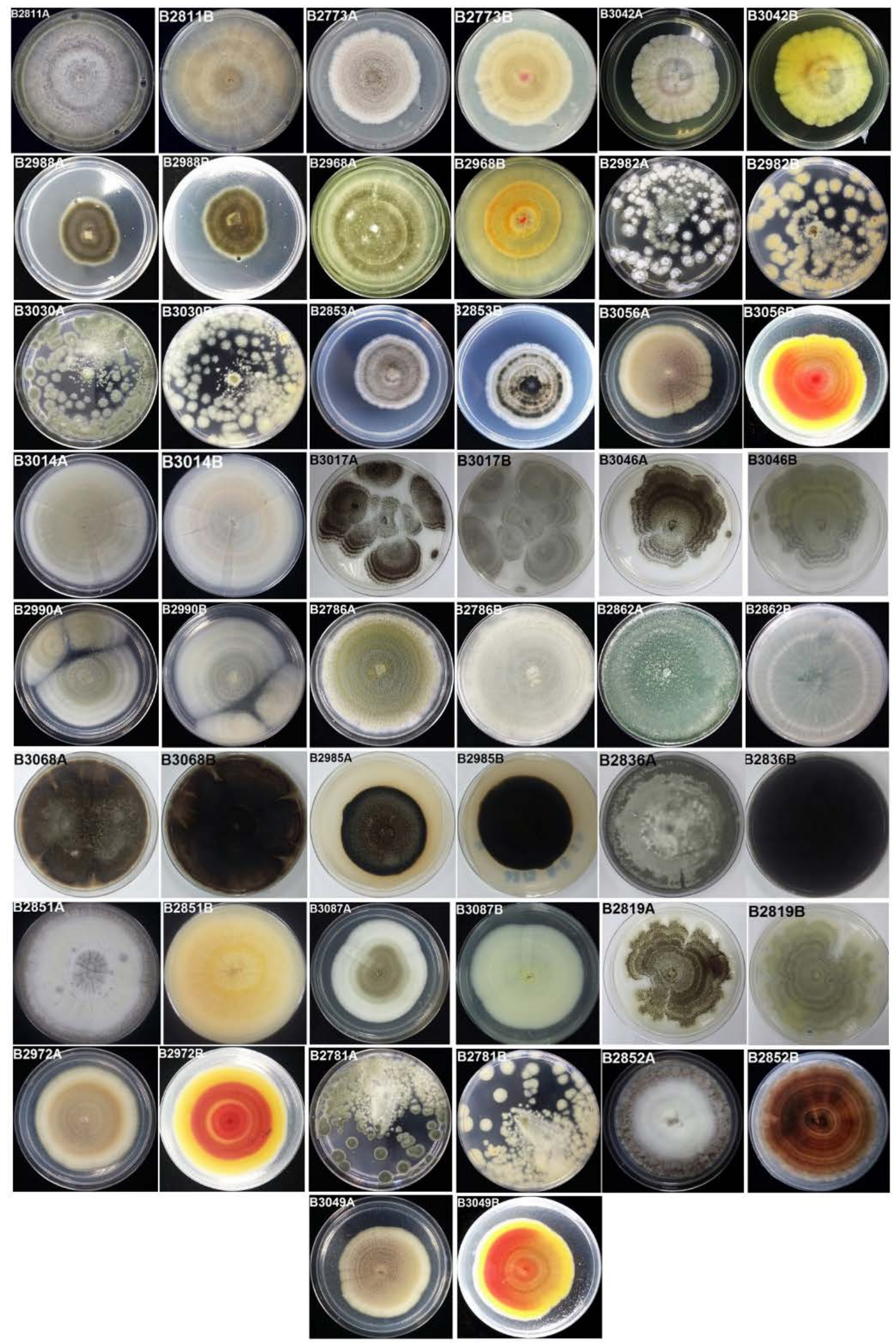

Fig. 1 - Colony features and pigmentation produced by all 25 isolates of microfungi on PDA. 
Colony growth of Curvularia species are rapid on PDA and produced cold grey or black color from the upper surface (Fig. 1). The pigmentation color from the reverse plate is black. Simple or geniculate conidiophore is possessed by Curvularia species, where they hold conidia at the tips of conidiophore. The conidia formed in ovoid and fusiform shape, where some of the conidia are slightly curved at the second cell with three septate.

Gliocladiopsis species produced white cottony morphology on the upper surface on PDA. The color of the colony pigmentation is grayish brown intermediate with walnut brown in concentric rings (Fig. 1). The penicillate and mononematous conidiophore holds conidia at the tips. The cylindrical conidia clump in a cluster when detached from conidiophore.

Metarhizium species produced grey and white color colony in a ring on the upper surface of PDA media (Fig. 1). The pigmentation on the reverse plate is orange glaze intermediate with naples yellow and white in a concentric ring. The branches conidiophore bears conidia at the ends in a false head arrangement. The conidia produced are in a cylindrical shape. Myrmecridium species, the colony grows moderately rapid on PDA with dark sepia and grey color on the upper surface due to compact submerged mycelium. The reverse plate is raw umber in color (Fig. 1). Myrmecridium species possess straight, unbranched conidiophores that hold conidia at the end of the conidiophore. The conidia form is in fusiform shape with smooth-walled.

Penicillium species, the colony produced a variety of color on the upper surface and the reverse plate of PDA (Fig. 1). Some of the colony produced concentric ring or limited aggregation, where the color of the pigmentation changed at mature. Penicillium species showed distinct microscopic characteristics from other genera, where they have various types of conidiophore. The conidiophore holds phialide that produced conidia at the end in chain arrangement. They possess monoverticillate, biverticillate, divaricate and quaterverticillate conidiophore that differs in term of their branching metulae and phialide from a main conidiophore. The conidia produced are globose and ellipsoidal in shape.

The colony of Scedosporium species is moderately grown on PDA with grey to white color on the upper surface of culture. The pigmentation color of the colony ranged from raw umber, white and warm grey with concentric rings on the reverse plate (Fig. 1). The microscopic features showed that the branches conidiophore bears the conidia in a single or small cluster. The branch or solitary phialide conidiophore bears the conidia in single or small cluster. Ovoid conidia with truncate bases are produced by Scedosporium species at the end of the conidiophore.

Trichoderma species grow rapidly on PDA, where they produced white, earth green to permanent green compact mycelial mass in the concentric ring. The colony produced colorless, white or cream pigmentation on the reverse plate (Fig. 1). The conidia arrangement of this genus is in clump formation known as a cluster. The conidiophore bears ellipsoidal to globose conidia at the tips of phialides. The isolates of Trichoderma species in this study showed irregularly verticillate conidiophore that branched repeatedly.

The size of ITS fragment was at 500-700 bp (Fig. 2). Based on the constructed phylogenetic analysis, the tree was divided into two branches which are clade I and clade II with one outgroup (Saccharomyces boulardii) clade (Fig. 3). Clade I was grouped into two subclades (subclade A and subclade B), where it showed $96 \%$ similarities between those two subclades. Subclade A is divided into two branches with $100 \%$ similarities between subclades A1 and A2, which placed genus Penicillium and Aspergillus. However, there are mixed of sequences in the branch that placed Penicillium species with $A$. nomius (B2786) and A. tamarii (B2990) in subclade A1, whereas $A$. aculeatinus (B2819) and A. aculeatus (B3017 and B3046) are closely related to 100\% similarities in subclade A2. Subclade B showed 87\% bootstrap value between subclade B1 and B2. Myrmecridium schulzeri was placed in subclade B1 with $100 \%$ similarities between isolated microfungi (M. schulzeri B2988) with GenBank reference (CBS 188.96). In subclade B2, isolates from Colletotrichum gloeosporioides (B3068), Scedosporium boydii (B2811 and B2773), Trichoderma koningiopsis (B2862), Clonostachys rosea (B3042), Gliocladiopsis peggii (B2852) and Metarhizium anisopliae (B2968) are classified together and closely related to each other with 89\% similarities. Clade II consists of two isolates of Curvularia lunata (B2836 and B2985) from 
isolates used and one isolates from BLAST search with 100\% similarities.

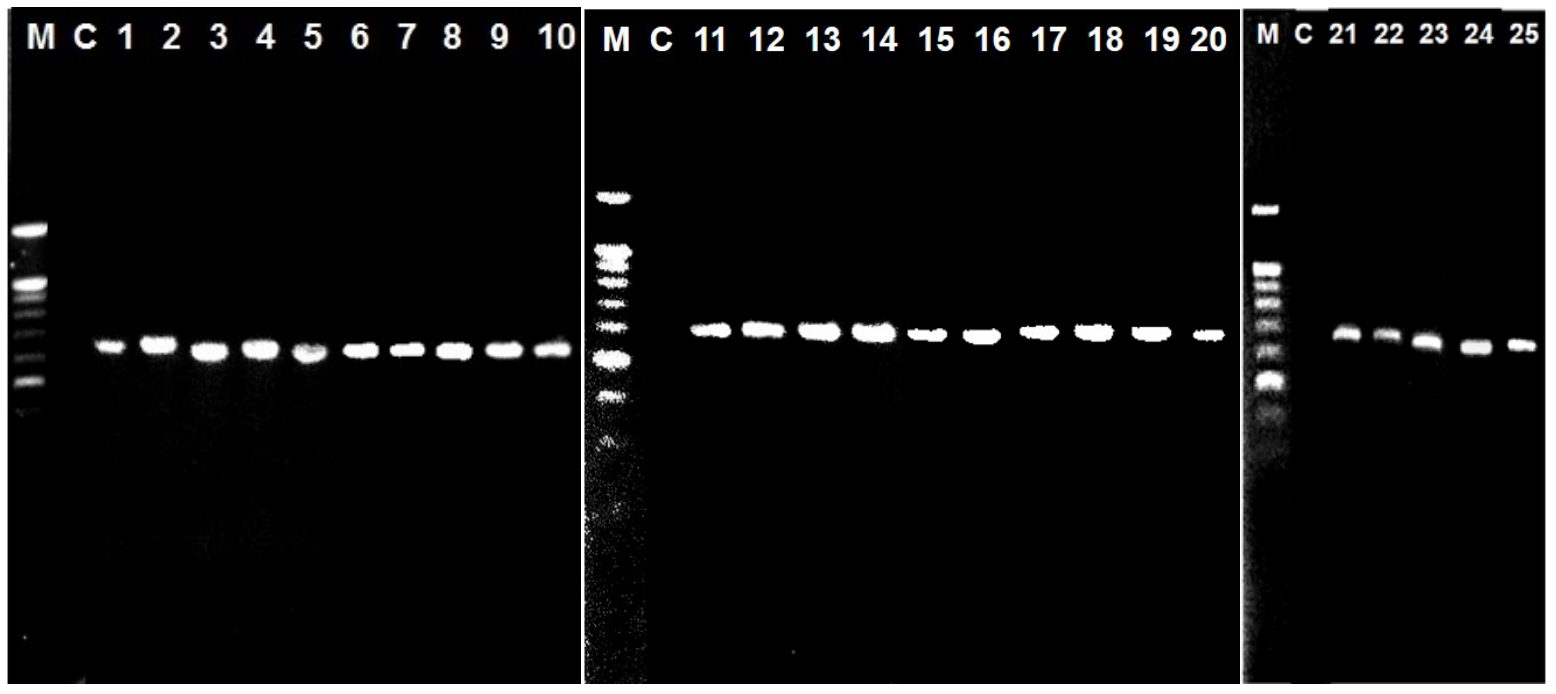

Fig. 2 - Banding patterns generated by primer ITS 1 and ITS 4 for each selected isolated microfungi. Lanes 1) Scedosporium boydii B2811, 2) Curvularia lunata B2985, 3) Clonostachys rosea B3042, 4) Gliocladiopsis peggii B2852, 5) Aspergillus aculeatinus B2819, 6) Colletotrichum gloeosporioides B2853, 7) Aspergillus aculeatus B3017, 8) Colletotrichum gloeosporioides B3068, 9) Aspergillus aculeatus B3046, 10) Penicillium singorense B2851, 11) Penicillium oxalicum B2781, 12) Penicillium javanicum B2972, 13) Curvularia lunata B2836, 14) Aspergillus nomius B2786, 15) Metarhizium anisopliae B2968, 16) Aspergillus tamarii B2990, 17) Penicillium rolfsii B3014, 18) Trichoderma koningiopsis B2862, 19) Myrmecridium schulzeri B2988, 20) Scedosporium boydii B2773, 21) Penicillium panissanguineum B3087, 22) Penicillium oxalicum B2982, 23) Penicillium oxalicum B3030, 24) Penicillium javanicum B3056, and 25) Penicillium javanicum B3049. $\mathrm{M}=100$ bp ladder. $\mathrm{C}=$ Control.

\section{Discussion}

The highest occurrence species of microfungi in recreational area (Bukit Ekspo) is supported with a study by Góralska et al. (2014) in which they found that the microfungi frequently obtained from the soil in playgrounds. This might be due to the high human activities in that area that can change the intensity of nutrients since it might rich in organic matter that can be a better reservoir which affected the populations of fungal.

The presence of some species of microfungi in agricultural areas (oil palm plantation) might be due to the differences in the level of gas, trace elements or heavy metal presence in the soil compared to other sampling locations. Kaltseis et al. (2009) reported that the level of ammonium from fertilizers affected the distributions of Scedosporium species, in which they are more abundant in the area with the highest level of ammonium. In this study, Metarhizium species only found in an oil palm plantation, where this is supported by Meyling \& Eilenberg (2006) which discovered a higher abundance of Metarhizium anisopliae in soils from the cultivated areas.

The residential area showed the least species of microfungi present in the soil. This might be due to the lower richness of plant presence in the surrounding area, where it leads to the lower soil fungal diversity in that area (Cline et al. 2017). However, the differences of the distribution patterns of genera in the four sites might be due to the differences level of chemical inputs and nutrient availability, $\mathrm{pH}$ level and moisture content in the soil, which should be considered for future study.

The presence of Aspergillus, Colletotrichum, Curvularia, Penicillium and Trichoderma species in the soil are parallel with the previous studies by Wuczkowski et al. (2004), Ilhan et al. (2006) and Raja et al. (2017). Colletotrichum species were obtained in the present study, which is parallel to the previous study conducted by Raja et al. (2017) from the soil in Chennai, India. Ashok et al. (2015) recorded three species of Curvularia from the soil in India. According to 
Latiffah et al. (2011), Curvularia species are rarely recorded in high occurrence in soil. This is supported by the low percentage of isolates Curvularia species found in crop fields at Salur Mandar (Gaddeyya et al. 2012).

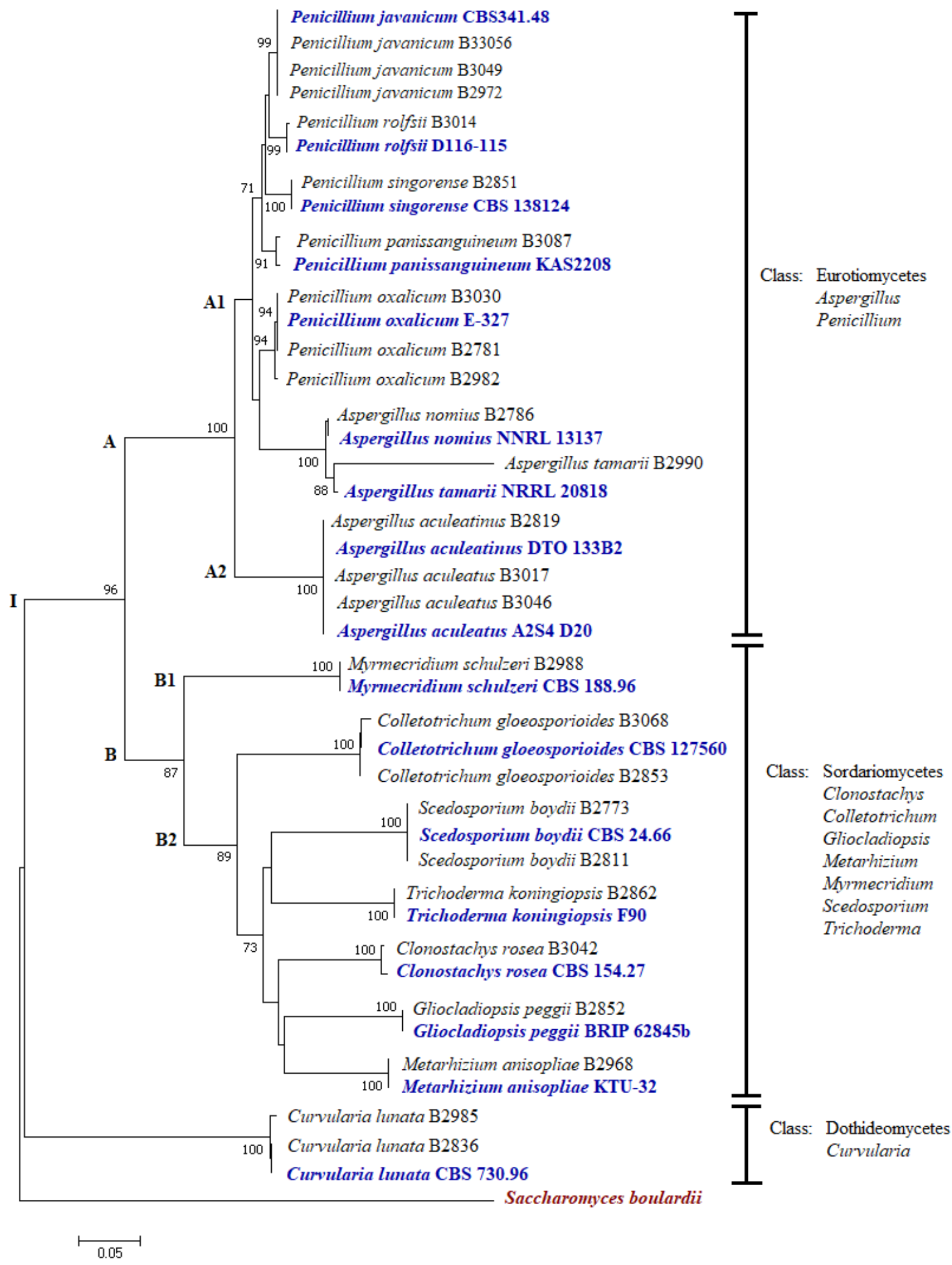

Fig. 3 - The phylogenetic tree was constructed by using Neighbor-Joining (NJ) method for 43 isolates (25 isolates used and 18 isolates control) of microfungi based on ITS sequence analysis. Saccharomyces boulardii is used as the outgroup. 
Clonostachys species were found and the identification of this genus is referring to the branching patterns of primary and secondary conidiophores (Schrocrs 2001). Previously, Afshari \& Hemmati (2017) reported that Clonostachys species were isolated from soil and plant materials such as decaying leaves and tree as saprotrophs. The distribution of genus Clonostachys in the present study is low may be due to the less existence of organic matter at sampling sites since they depend on the organic matter for carbon sources (Ravnskov et al. 2006).

Gliocladiopsis species also present in Serdang soil community. The penicillate and mononematous conidiophore is produced by the Mymecridium species isolates of the present study, where this is supported by Lombard \& Crous (2012). Fatima et al. (2008) discovered that the findings of this genus from the soil are rare with the usage of soil dilution plate method. Mymecridium species found in the present study and formed fusiform conidia with no septum, where this is supported by Peintner et al. (2016). Previously, Romão-Dumaresq et al. (2016) found only one isolate of this genus from both rhizosphere and root around sugarcane.

Scedosporium species is distinguished by having more irregular hyphae with multiple branching at acute angles (Kimura et al. 2010). Harun et al. (2010) stated that the colonies of Scedosporium species are often undetected due to the prodigious growth of rapid-growing filamentous fungi in soil including Aspergillus spp. According to Rougeron et al. (2017), genus Scedosporium acts as soil saprophytes. However, they are less frequently experienced in the tropics including Asia but frequently encountered in temperate climates. Cortez et al. (2008) mentioned that Scedosporium species can withstand high temperature and have the ability to live in a habitat that provided very low oxygen pressure. In addition, anthropogenic activity on the ecology involved does influences the distribution of Scedosporium species, where some of the species present in high human activity area while the other exists in low human activity area (Rougeron et al. 2017).

This study revealed that various microfungi were isolated from the soil samples collected from Serdang, Selangor. The 18 species were successfully identified are Aspergillus aculeatinus, A. aculeatus, A. nomius, A. tamari, Clonostachys rosea $f$. catenulata, Colletotrichum gloeosporioides, Curvularia lunata, Gliocladiopsis peggii, Metarhizium anisopliae, Myrmecridium schulzeri, Penicillium javanicum, $P$. oxalicum, $P$. panissanguineum, $P$. rolfsii, $P$. singorense, Scedosporium boydii and Trichoderma koningiopsis. The information obtained can be used as a baseline for future studies on the occurrence and species diversity of microfungi isolated from soil. The distribution of the microfungi assemblages are mainly affected by anthropogenic activities. However, many parameters could affect the distribution and need to be considered for further study.

\section{Acknowledgements}

The authors thank all staff of the Department of Biology, Faculty of Science, Universiti Putra Malaysia for their facilities during the study. This work was partially supported by Universiti Putra Malaysia (UPM/700-2/1/GP-IPS/2017/9577700) on Trichoderma isolation part.

\section{References}

Afshari N, Hemmati R. 2017 - First report of the occurrence and pathogenicity of Clonostachys rosea on faba bean. Australasian Plant Pathology 46(3), 231-234.

Apinis AE. 1963 - Occurrence of thermophilous microfungi in certain allvial soils near Nottingham. Nova Hedwigia 5, 57-78.

Ashok G, Senthilkumar G, Panneerselvam A. 2015 - Diversity and seasonal variation of soil fungi isolated from coastal area of Tuticorin Dt., Tamil Nadu, India. International Journal of Current Microbiology and Applied Sciences 4(10), 161-178.

Cline LC, Hobbie SE, Madritch MD, Buyarski CR et al. 2017 - Resource availability underlies the plant-fungal diversity relationship in a grassland ecosystem. Ecology 99(1), 204-216.

Cortez KJ, Roilides E, Quiroz-Telles F, Meletiadis J et al. 2008 - Infections caused by Scedosporium spp. Clinical Microbiology Reviews 21(1), 157-197. 
Fatima MS, Huising MEJ, Bignell DE. 2008 - A handbook of tropical soil biology. Sampling and characterization of below-ground biodiversity. Earthscan Publisher, London, UK. p218.

Fong YK, Anuar S, Lim HP, Tham FY, Sanderson FR. 2000 - A modified filter paper technique for long-term preservation of some fungal cultures. Mycologist 14(3), 127-130.

Gaddeyya G, Niharika PS, Bharathi P, Ratna Kumar PK. 2012 - Isolation and identification of soil mycoflora in different crop fields at Salur Mandal. Advances in Applied Science Research 3(45), 2020-2026.

Góralska K, Kurnatowski P, Błaszkowska J, Wójcik A. 2014 - Soil of recreational areas as a reservoir of keratinolytic mould fungi and dermatophytes potentially pathogenic for humans. Polish Journal of Environmental Study 24(3), 993-1002.

Harun A, Gilgado F, Chen SC, Meyer W. 2010 - Abundance of Pseudallescheria/Scedosporium species in the Australian urban environment suggests a possible source for scedosporiosis including the colonization of airways in cystic fibrosis. Medical Mycology 48(1), 70-76.

Hyde KD. 2003 - Mycology in the future in the Asia-Pacific region. Fungal Diversity 13, 59-68.

Ilhan S, Demirel R, Asan A, Baycu C, Kinaci E. 2006 - Colonial and morphological characteristics of some microfungal species isolated from agricultural soils in Eskisehir Province (Turkey). Turkish Journal of Botany 30, 95-104.

Kaltseis J, Rainer J, De Hoog GS. 2009 - Ecology of Pseudallescheria and Scedosporium species in human-dominated and natural environments and their distribution in clinical samples. Medical Mycology 47(Special Issue), 398-405.

Kimura M, Maenishi O, Ito H, Ohkusu K. 2010 - Unique histological characteristics of Scedosporium that could aid in its identification. Pathology International 60, 131-136.

Kumar S, Stecher G, Tamura K. 2016 - MEGA7: Molecular evolutionary genetics analysis version 7.0 for bigger datasets. Molecular Biology and Evolution 33(7), 1870-1874.

Latiffah Z, Teh LY, Maziah Z, Baharuddin S. 2011 - Diversity of microfungi in sandy beach soil of Teluk Aling, Pulau Pinang. Tropical Life Science Research 22(1), 71-80.

Lee SS, Alias SA, Jones EGB, Zainuddin N, Chan HT. 2012 - Checklist of Fungi of Malaysia, Issue/No. 132. Forest Research Institute Malaysia (FRIM), Malaysia. pp. 556.

Lombard L, Crous PW. 2012 - Phylogeny and taxonomy of the genus Gliocladiopsis. Persoonia 28, 25-33.

Maron P, Sarr A, Kaisermann A, Lévêque J et al. 2018 - High microbial diversity promotes soil ecosystem functioning. Applied and Environmental Microbiology 84(9), e02738-17

Meyling NV, Eilenberg J. 2006 - Occurrence and distribution of soil borne entomopathogenic fungi within a single organic agroecosystem Agriculture Ecosystems and Environment 113(1):336-341

Mueller GM, Bills GF, Foster MS. 2004 - Biodiversity of fungi: Inventory and monitoring method. Academic Press, US. p777.

Oladele KO, Siew QY, Zakry FAA, Lan JCW, Ling TC. 2014 - Overview of citric acid production from Aspergillus niger. Journal of Frontiers in Life Science 8, 271-283.

Peintner U, Knapp M, Fleischer V, Walch G, Dresch P. 2016 - Myrmecridium hiemale sp. nov. from snow-covered alpine soil is the first eurypsychrophile in this genus of anamorphic fungi. International Journal of Systematic and Evolutionary Microbiology 66, 2592-2598.

Raja M, Praveena G, William SJ. 2017 - Isolation and identification of fungi from soil in Loyola College Campus, Chennai, India. International Journal of Current Microbiology and Applied Science 6(2), 1789-1795.

Ravnskov S, Jensen B, Knudsen IMB, Bodker L et al. 2006 - Soil inoculation with the biocontrol agent Clonostachys rosea and the mycorrhizal fungus Glomus intraradices results in mutual inhibition, plant growth promotion and alteration of soil microbial communities. Soil Biology and Biochemistry 38(12), 3453-3462.

Romão-Dumaresq AS, Dourado MN, de Lima Fávaro LC, Mendes R et al. 2016 - Diversity and cultivated fungi associated with conventional and transgenic sugarcane and the interaction between endophytic Trichoderma virens and the host plant. PLoS ONE 11(7), e0158974. 
Ropars J, López-Villavicencio M, Snirc A, Lacoste S, Giraud T. 2017 - Blue cheese-making has shaped the population genetic structure of the mould Penicillium roquefortii. PLoS ONE 12(3), e0171387.

Rougeron A, Giraud S, Alastruey-Izquierdo A, Cano-Lira J et al. 2017 - Ecology of Scedosporium species: Present knowledge and future research. Mycopathologia 181(1), 185-200.

Schrocrs HJ. 2001 - A monograph of Bionectria (Ascomycota, Hypocreales, Bionectriaceae) and its Clonostachys anamorphs. Studies in Mycology 46:1-96.

Tamura K, Stecher G, Peterson D, Filipski A, Kumar S. 2013 - MEGA6: Molecular Evolutionary Genetics Analysis Version 6.0. Molecular Biology and Evolution 30(12), 2725-2729.

Tedersoo L, Bahram M, Põlme S, Kõljalg U et al. 2014 - Fungal biogeography. Global diversity and geography of soil fungi. Science 346(6213), 1256688.

White TJ, Bruns T, Lee S, Taylor J. 1990 - Amplification and direct sequencing of fungal ribosomal RNA genes for phylogenetics. In: PCR Protocols: a guide to methods and applications. (Innis MA, Gelfand DH, Sninsky JJ, White TJ, eds). Academic Press, New York, USA. pp. 315-322.

Wuczkowski M, Sterflinger K, Kraus GF, Klug B, Prillinger H. 2004 - Diversity of microfungi and yeasts in soils of the alluvial zone national park along the river Danube downstream of Vienna, Austria. The Soil Culture 54(2), 109-117.

Ziemons S, Koutsantas K, Becker K, Dahlmann T, Kuck U. 2017 - Penicillin production in industrial strain Penicillium chrysogenum P2niaD18 is not dependent on the copy number of biosynthesis genes. BMC Biotechnology 17(16), 1-11.

Zifcakova L, Vetrovsky T, Howe A, Baldrian P. 2016 - Microbial activity in forest soil reflects the changes in ecosystem properties between summer and winter. Environmental Microbiology 18, 288-301. 